\title{
Vigabatrin Decreases Cholecystokinin- Tetrapeptide (CCK-4) Induced Panic in Healthy Volunteers
}

Peter Zwanzger, M.D., Thomas C. Baghai, M.D., Cornelius Schuele, M.D., Andreas Ströhle, M.D., Frank Padberg, M.D., Norbert Kathmann, Ph.D., Markus Schwarz, M.D., Hans-Jürgen Möller, M.D., and Rainer Rupprecht, M.D.

Vigabatrin increases gamma aminobutyric acid (GABA) levels by irreversible inhibition of the GABA-catabolizing enzyme GABA-transaminase (GABA-T). Preclinical studies suggest anxiolytic effects in vigabatrin treated rats. Anxiolytic effects in patients with panic disorder (PD) could therefore be expected. To evaluate putative anxiolytic properties of vigabatrin in humans, CCK-4-induced panic symptoms were studied in healthy volunteers before and after vigabatrin treatment. After placebo-controlled administration of $50 \mu \mathrm{g} C \mathrm{CK}-4$, ten healthy volunteers received vigabatrin for seven days with a daily dosage of $2 \mathrm{~g}$. The treatment period was followed by a second CCK-4 challenge. Panic and anxiety were assessed using the Acute Panic Inventory (API) score and a DSM-IV derived panicsymptom-scale (PSS). ACTH and cortisol plasma levels were determined during the CCK-4 challenge. All subjects reported a marked reduction of CCK-4-induced panic symptoms and anxiety after seven days of vigabatrin treatment both in the API- and PSS-scores. Moreover, there was a significant attenuation of CCK-induced elevation of ACTH and cortisol levels following vigabatrin treatment. In conclusion, our data show that GABAtransaminase inhibitors exert anxiolytic effects in CCK4-induced panic in healthy volunteers and suggest that GABA transaminase inhibitors might be useful in ameliorating panic symptoms also in patients with $P D$.

[Neuropsychopharmacology 25:699-703, 2001] (C) 2001 American College of Neuropsychopharmacology. Published by Elsevier Science Inc.
KEY WORDS: Panic attacks; Cholecystokinin-tetrapeptide (CCK-4); Vigabatrin; ACTH; Cortisol; HPA system; $G A B A$

From the Department of Psychiatry, University of Munich, Nussbaumstrasse 7, 80336 Munich, Germany (PZ, TCB, CS, FP, NK, MS, H-JM, RR), and the Max Planck Institute of Psychiatry, Kraepelinstrasse 2, 80804 Munich, Germany (AS)

Address correspondence to: Peter Zwanzger, M.D., Department of Psychiatry, University of Munich, Nussbaumstrasse 7, 80336 Munich, Germany, Tel.: + 49895160 5813, Fax: + 49895160 5391, email: zwanzger@psy.med.uni-muenchen.de

Received September 27, 2000; revised March 22, 2001; accepted April 2, 2001.

Online publication: 4/12/01 at www.acnp.org/citations/Npp 04030198 .
The new antiepileptic drug vigabatrin is a selective irreversible inhibitor of GABA-transaminase (GABA-T), the main degradative enzyme of GABA (Harden 1994). Vigabatrin increases CSF GABA levels by 2 to 3-fold when administered in anticonvulsant doses (Ben-Menachem 1989). Preclinical studies suggest that vigabatrin has anxiolytic properties in addition to its anticonvulsant effects. Sayin et al. (1992) compared the anxiolytic effects of diazepam and vigabatrin in rats and found a significant decrease of anxiety with both substances using the elevated plus maze test. Sherif and colleagues investigated the effects of GABA-transaminase inhibition on exploratory behaviour in socially isolated rats using both the elevated plus maze and the open field 
test (Sherif et al. 1994; Sherif and Oreland 1995). Despite these promising results in animal models it is still unclear whether vigabatrin exerts anxiolytic properties also in humans.

CCK-4 has potent anxiogenic properties both in patients with panic disorder and in healthy volunteers (Bradwejn et al. 1990; Bradwejn et al. 1991a; Bradwejn et al. 1991b). Recent data suggest that CCK-4-induced panic is attenuated by antipanic treatment. A decrease of the anxiogenic effects of CCK-4 has been shown after treatment with benzodiazepines in healthy volunteers (de Montigny 1989). Moreover, antidepressants that are commonly used as antipanic treatment, e.g. imipramine (Bradwejn and Koszycki 1994a), fluvoxamine (van Megen etal. 1997) and citalopram (Shlik et al. 1997) reduced CCK-4-induced panic in patients with panic disorder.

CCK-4-induced panic appears to be a suitable model to assess anxiolytic properties of psychopharmacological drugs in humans. To evaluate the putative anxiolytic properties of the selective GABA transaminase inhibitor vigabatrin, we therefore studied the effects of treatment with vigabatrin for seven days on CCK-4-induced panic symptoms in healthy male volunteers.

\section{METHODS}

Ten male healthy volunteers (mean age $=30.7$ years, $\mathrm{SD}=7.04$ ) were studied. All subjects underwent a structured interview (SCID) (Wittchen et al 1996) by an experienced psychiatrist. Subjects were found to be free of any history of mental disorder or somatic disease by means of physical examination, electrocardiogram, electroencephalogram and routine laboratory testing. None reported a history of mental illness in first degree relatives. Any intake of opiates or benzodiazepines was ruled out for at least four weeks prior to baseline by urine toxicology screening. The protocol was approved by the local ethics committee for human experiments. After a complete description of the study all subjects gave their written informed consent. At day 0 and day 1 , subjects were challenged with CCK-4 or saline in a randomized order. From day 2 until day 9 subjects received vigabatrin (Sabril ${ }^{\circledR}$, Hoechst, Frankfurt, Germany) twice daily in a daily dose of $2 \mathrm{~g}$, which corresponds to $30 \mathrm{mg} / \mathrm{kg}$ body weight as used for anticonvulsive treatment. After seven days of treatment subjects were rechallenged with saline on day 8 and with CCK-4 on day 9. Two hours prior to every challenge subjects were seated in a bed in an upright position in a quiet room. An intravenous catheter was inserted into a forearm vein. At 10:00 A.M. $50 \mu \mathrm{g}$ CCK-4 (Clinalfa, Lauelfingen, Switzerland, dissolved in $10 \mathrm{ml}$ $0.9 \%$ saline) or saline ( $10 \mathrm{ml} 0.9 \%$ saline) were administered as a bolus injection. Severity of panic symptoms was assessed with the Acute Panic Inventory (API) (Dillon et al. 1987) and a DSM-IV-derived Panic Symptom Scale (PSS) (Bradwejn et al. 1991a) before and after CCK-4 administration at the time points 10:00 (baseline), 10:05, 10:10, 10:20, 10:30 and 11:00 A.M. The maximum intensity during the challenge used for analysis. For evaluation of subjective anxiety a $100-\mathrm{mm}$ visualanalogue scale (VAS) for anxiety was used. Heart rate was recorded with a DATEX-OHMEDA light monitor (Datex-Ohmeda, Finland) continuously during the whole challenge. Blood samples were taken at 10:00 (baseline), 10:05, 10:10, 10:20, 10:30 and 11:00 A.M. for determination of plasma cortisol and ACTH concentrations. ACTH plasma immunoreactivity was measured using a commercially available immunoradiometric assay (ACTH 100T Kit, Nichols Institute Diagnostics, USA) with a sensitivity of $0.11 \mathrm{pmol} / 1$. For cortisol determination a commercial radioimmunoassay kit was employed (Cortisol-RIA, DPC Biermann, Germany) with a sensitivity of $8.27 \mathrm{nmol} / \mathrm{l}$. Our intra- and interassay coefficients of variation were below $5 \%$. Areas under the curve (AUC) for cortisol and ACTH blood concentration vs. time were calculated by numerical integration using the trapezoidal rule. To control the subjects compliance to drug intake vigabatrin serum levels were determined by high performance liquid chromatography (HPLC) (Figure 1).

Results are expressed as mean \pm SEM. To evaluate significant time effects on ACTH and cortisol concentrations after CCK-4 or saline injection, ANOVA with repeated measurements with time as within-subject factor was performed. To test for treatment effects of vigabatrin on clinical and endocrinological variables under CCK-4 challenge the data collected on CCK-4 challenge days before and after vigabatrin treatment were used. Clinical rating scores, heart rate, ACTH and cortisol AUCs and peak plasma concentrations were analyzed by ANOVA with a repeated measures design with treatment as within subject factor. To approach normality and homogeneity in the data, the variables of plasma hormonal concentrations used the analysis were transformed with the log-transformation $\left(x^{*}=\ln \right.$ [x]) before entering the analysis. Alpha $=0.05$ was accepted as the nominal level of significance.

\section{RESULTS}

The maximum intensity of symptoms provoked by CCK-4 was observed within the first five minutes after injection. There was no difference between responses to CCK-4 on day 0 or day 1 . All subjects reported a marked reduction of CCK-4-induced panic and anxiety after one week of vigabatrin treatment. Compared to the first CCK-4 challenge the number of reported PSS symptoms decreased by $50 \%$ from $9.4 \pm 0.9$ (range 5 to 


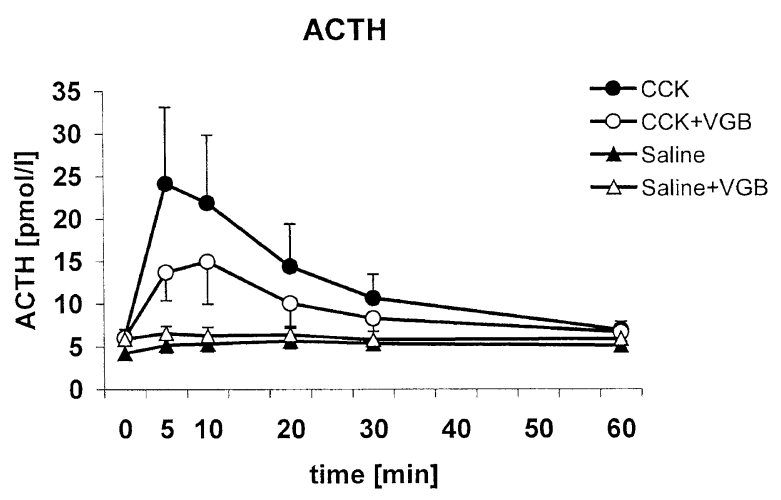

Cortisol

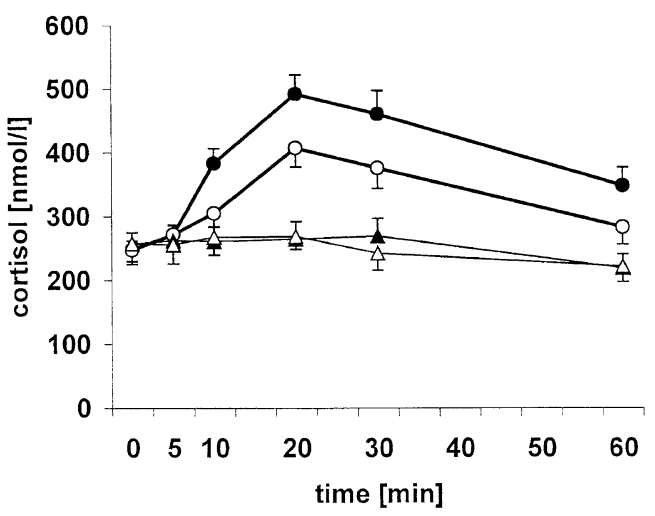

Figure 1. Mean \pm SEM plasma concentrations of cortisol and $\mathrm{ACTH}$ in 10 healthy volunteers after administration of $50 \mu \mathrm{g}$ CCK- 4 before and after vigabatrin treatment.

13) to $4.7 \pm 1.0$ (range 0 to 6 ) after vigabatrin treatment $(\mathrm{F}(1,9)=45.08, p<.001)$. PSS sumscores decreased by $54 \%$ from $19.7 \pm 2.8$ (range 3 to 31 ) to $9 \pm 2.2$ (range 0 to 25) $(\mathrm{F}(1,9)=9.2, p=.014)$. The mean API sumscore decreased significantly by $45 \%$ from $24.0 \pm 3.3$ (range 10 to 38 ) to $13.2 \pm 3.5$ (range 0 to 42$)(F(1,9)=18.96, p=$ .002). Moreover, subjects reported a significant reduction of VAS-scores for anxiety from $52.0 \pm 6.6$ (range 30 to 90 ) to $26.5 \pm 5.7$ (range 0 to 60$)(\mathrm{F}(1,9)=9.56, p=$ .013). None reported an increase in panic during the second challenge compared to the first one.

CCK-4-induced physiological parameters such as increase in heart rate were not significantly affected by vigabatrin treatment. The maximum heart rate decreased nonsignificantly from $89 \pm 16 / \mathrm{min}$ to $81 \pm 19 / \mathrm{min}$ after vigabatrin intake.

During the placebo challenge subjects did not report marked panic symptoms. The maximum API-score ranged from 0 to 3 (mean $0.7 \pm 0.9$ ) before and from 0 to 8 (mean $2.8 \pm 3.4$ ) after vigabatrin treatment. The maximum PSS-score ranged from 0 to 3 (mean $1.3 \pm 0.9$ ) be- fore and from 0 to 2 (mean $0.8 \pm 0.6$ ) after vigabatrin treatment. The maximal VAS-score ranged from 0 to 6 (mean $1.1 \pm 2.3$ ) before and from 0 to 20 (mean $5.7 \pm$ 8.2) after vigabatrin intake.

Cortisol and ACTH showed a marked and significant increase over baseline during the CCK-4 challenge before vigabatrin treatment. ANOVA for repeated measurement revealed a significant time effect for cortisol and ACTH (cortisol: $\mathrm{F}(5,5)=60.6, p<.001$, ACTH: F $(5,5)=5.9, p=.036)$. In contrast, no significant time effects were observed for either ACTH or cortisol levels after saline injection. After seven days of vigabatrin treatment, both cortisol and ACTH responses to CCK-4 challenge showed a significant blunting when compared to pretreatment levels. AUC of cortisol decreased from $24203 \pm 1444$ to $20096 \pm 1335 \mathrm{nmol} / 1^{*} \min (\mathrm{F}(1,9)=$ $11.77, p=.008)$. AUC of ACTH diminished from $761 \pm$ 221 to $562 \pm 141 \mathrm{pmol} / 1 * \min (\mathrm{F}(1,9)=9.1, p=.015)$. Also peak cortisol levels showed a significant reduction from $509.6 \pm 35.8$ to $410.2 \pm 28.6 \mathrm{nmol} / \mathrm{l}(\mathrm{F}(1,9)=12.79$, $p=.006)$. The ACTH peak decreased from $25.3 \pm 8.8$ to $16.2 \pm 5.0 \mathrm{pmol} / 1(\mathrm{~F}(1,9)=7.49, p=.023)$. However, cortisol and ACTH levels at baseline and after saline injection did not differ before and after vigabatrin treatment (Figure 1).

There was no correlation of anxiolytic effects of vigabatrin and vigabatrin plasma levels. Moreover, there were no significant correlations between attenuation of $\mathrm{ACTH}$ and cortisol levels and the psychometric data. All subjects were compliant with regard to vigabatrin intake as demonstrated by measures of vigabatrin plasma concentrations (mean $11.80 \mu \mathrm{g} / \mathrm{ml}$, SD $4.14 \mu \mathrm{g} /$ $\mathrm{ml})$. Apart from slight vertigo in the first days of treatment, vigabatrin was well tolerated by all subjects.

\section{DISCUSSION}

The major finding of our study is that treatment with vigabatrin leads to a marked and significant decrease of CCK-4-induced panic attacks. This is demonstrated by the decrease of the API, PSS and VAS scores following CCK-4 challenge after vigabatrin treatment. Although it has to be considered that our study was not placebo-controlled and a certain placebo effect cannot be ruled out, the pronounced anxiolytic effects of vigabatrin are unlikely to be merely caused by a placebo effect. Previous studies investigating the effects of fluvoxamine on CCK4-induced panic in a placebo-controlled study revealed a marked effect of fluvoxamine on CCK-4-induced panic in view of a slight and non-significant effect in the placebo group (van Megen et al. 1997). The CCK-4-induced panic rate dropped significantly from $76 \%$ to $29 \%$ within eight weeks of treatment in the fluvoxamine group, whereas there was only a nonsignificant decrease from $67 \%$ to $56 \%$ in the placebo group. 
In contrast to treatment with imipramine or fluvoxamine (Bradwejn and Koszycki 1994b; van Megen et al. 1997), we found no statistically significant effect of vigabatrin on the physiological response to CCK-4 such as heart rate.

Our findings are in agreement with recent reports describing anxiolytic effects of vigabatrin treatment in animals. These data show a significant improvement of explorative behaviour with vigabatrin in socially isolated rats using the elevated plus maze and the open field test after administration of vigabatrin (Sherif et al. 1994; Sherif and Oreland 1995; Sayin et al. 1992). Moreover, this finding is in line with effects of other GABAergic agents in humans. For example, benzodiazepines have been shown to attenuate CCK-4-induced panic in healthy volunteers. de Montigny (1989) showed an attenuation of CCK-4-induced panic symptoms by lorazepam in four subjects. Moreover, preclinical studies report an antagonization of CCK-8 induced activation of rat hippocampal pyramidal neurons after administration of benzodiazepines (Bradwejn and de Montigny 1984). On the other hand, a provocation of panic symptoms with flumazenil in patients with panic disorder has been described (Nutt et al. 1990).

These results suggest that GABAergic mechanisms play an important role in the modulation of CCK4-induced panic. CCK is localized in GABA-synthesizing neurons in the cerebral cortex, hippocampus and basolateral amygdala and its release is under tonic control by GABA mediated mechanisms (Harro et al. 1993). Thus, also the functional neuroanatomy of CCK-4 and the GABAergic system underlines the importance of GABA for CCK-4-induced anxiety. Besides the GABAergic system, also the serotonergic system is involved in the neurobiology of CCK-4-induced anxiety (Harro et al. 1993). Treatment with serotonin reuptake inhibitors (SSRIs) commonly used for antipanic treatment reduces or even blocks CCK-4-induced panic in patients with panic disorder (van Megen et al. 1997; Bradwejn and Koszycki 1994b; Shlik et al. 1997).

After administration of CCK-4, all subjects showed a marked increase in ACTH and cortisol plasma levels. These findings are in agreement with prior studies that reported an elevation of cortisol and ACTH after CCK-4 challenge in healthy subjects (de Montigny 1989; Koszycki et al. 1998). In addition, elevated levels of ACTH and cortisol were noted after administration of the synthetic analogue of the cholecystokinin pentagastrin in healthy volunteers (Abelson et al. 1991; Degli Uberti et al. 1983).

Moreover, there is increasing evidence that the neuroendocrine response of the hypothalamic-pituitaryadrenal (HPA) system might discriminate between CCK4-panickers and nonpanickers. Koszycki et al. (1998) showed that the ACTH increase after CCK-4 administration is significantly enhanced in healthy subjects who panicked after CCK-4 administration, unlike in subjects who did not panic. Also, in patients with panic disorder the elevation of ACTH plasma levels following CCK-4 challenge was reported to be significantly higher in patients with panic attacks than those without panic attacks (Ströhle et al. 2000; Flint et al. 2000). Thus, the activity of the HPA system following CCK-4 challenge appears to somehow reflect the anxiety response to CCK-4-induced panic. In the present study we found that stimulation of ACTH and cortisol levels by CCK-4 was significantly blunted after vigabatrin treatment. This reduction in HPA activity corresponds to our clinical results; however, no firm relationship between the effects of vigabatrin on HPA system activity and psychometric data could be established in our study. It is well known that the activity of the HPA system is inhibited by GABAergic mechanisms (Holsboer 1998). In contrast, heart rate has been shown to increase following treatment with benzodiazepines in rats (Castro et al. 1999) and humans (Farmer et al. 1998) which is in line with the differential effects of vigabatrin on HPA system activity and heart rate.

Treatment with vigabatrin leads to an increase of GABA through inhibition of GABA-T. GABA itself acts through a binding site different from that of benzodiazepines at the $\mathrm{GABA}_{\mathrm{A}}$ receptor, which offers a new pharmacological principle in the treatment of anxiety disorders. In fact, sleep studies have shown that agonists for the GABA binding site produce a much more favorable sleep EEG profile than benzodiazepines with no REM suppression, an enhancement of slow wave activity during non REM sleep and no withdrawal effects (Lancel and Faulhaber 1996). Indeed, first clinical experiences using vigabatrin show a marked reduction of panic and agoraphobia in patients with panic disorder (Zwanzger et al. 2001). However, the occurrence of visual field constrictions render the long term use of vigabatrin problematic (Manuchehri et al. 2000). Thus, future studies should also focus on other drugs targeting the GABA binding site of the $\mathrm{GABA}_{\mathrm{A}}$ receptor using experimentally induced panic paradigms.

In summary, treatment with the selective GABAtransaminase-inhibitor vigabatrin leads to a marked and significant reduction of CCK-4-induced panic symptoms in healthy volunteers. Moreover, we found a significantly blunted CCK-4-induced ACTH and cortisol response after vigabatrin treatment. Thus, targeting the GABA binding site of the $\mathrm{GABA}_{\mathrm{A}}$ receptor as achieved by GABA-T inhibitors could be an new strategy for the treatment of panic disorder. Because there is no risk of dependency the use of GABA-transaminase inhibitors could be an alternative treatment strategy to benzodiazepines. In view of the demonstrated anxiolytic properties in healthy volunteers, future studies should also assess the potential anxiolytic effects of GABA-T inhibitors in patients with panic disorder. 


\section{ACKNOWLEDGMENTS}

The authors thank Angela Johnson for technical assistance.

\section{REFERENCES}

Abelson JL, Nesse RM, Vinik A (1991): Stimulation of corticotropin release by pentagastrin in normal subjects and patients with panic disorder. Biol Psychiatry 29(12):1220 1223

Ben-Menachem E (1989): Pharmacokinetic effects of vigabatrin on cerebrospinal fluid amino acids in humans. Epilepsia 30 Suppl 3:S12-S14

Bradwejn J, de Montigny C (1984): Benzodiazepines antagonize cholecystokinin-induced activation of rat hippocampal neurones. Nature 312:363-364

Bradwejn J, Koszycki D (1994b): Imipramine antagonism of the panicogenic effects of cholecystokinin tetrapeptide in panic disorder patients. Am J Psychiatry 151:261-263

Bradwejn J, Koszycki D (1994a): The cholecystokinin hypothesis of anxiety and panic disorder. Ann $\mathrm{N} \mathrm{Y}$ Acad Sci 713:273-82

Bradwejn J, Koszycki D, Bourin M (1991a): Dose ranging study of the effects of cholecystokinin in healthy volunteers. J Psychiatry Neurosci 16:91-95

Bradwejn J, Koszycki D, Meterissian G (1990): Cholecystokinin-tetrapeptide induces panic attacks in patients with panic disorder. Can J Psychiatry 35:83-85

Bradwejn J, Koszycki D, Shriqui C (1991b): Enhanced sensitivity to cholecystokinin tetrapeptide in panic disorder. Clinical and behavioral findings. Arch Gen Psychiatry 48:603-610

Castro JL, Ricci D, Taira CA, Ramirez A (1999): Central benzodiazepine involvement in clonidine cardiovascular actions. Can J Physiol Pharmacol 77:844-851

de Montigny C (1989): Cholecystokinin tetrapeptide induces panic-like attacks in healthy volunteers. Arch Gen Psychiatry 46:511-517

Degli Uberti EC, Trasforini G, Margutti AR, Rotola CA, Pansini R (1983): Effect of pentagastrin on adrenocorticotropin hormone and thyroid-stimulating hormone release in normal subjects. Horm Res 17:74-77

Dillon DJ, Gorman JM, Liebowitz MR, Fyer AJ, Klein DF (1987): Measurement of lactate-induced panic and anxiety. Psychiatry Res 20:97-105

Farmer MR, Vaile JC, Osman F, Ross HF, Townend JN, Coote JH (1998): A central gamma-aminobutyric mechanism in cardiac vagal control in man revealed by studies with intravenous midazolam. Clin Sci 95:241-248

Flint AJ, Koszycki D, Bradwejn J, Vaccarino FJ (2000): Neurohormonal responses to cholecystokinin tetrapeptide: a comparison of younger and older healthy subjects. Psychoneuroendocrinology 25:633-647

Harden CL (1994): New antiepileptic drugs. Neurology 44:787-795

Harro J, Vasar E, Bradwejn J (1993): CCK in animal and human research on anxiety. Trends Pharmacol Sci $14: 244-249$

Holsboer F (1998): The rationale for corticotropin-releasing hormone receptor (CRH-R) antagonists to treat depression and anxiety. J Psychiatric Res 33:181-214.

Koszycki D, Zacharko RM, Le Melledo JM, Bradwejn J (1998): Behavioral, cardiovascular, and neuroendocrine profiles following CCK-4 challenge in healthy volunteers: a comparison of panickers and nonpanickers. Depress Anxiety 8:1-7

Lancel M, Faulhaber J (1996): The $\mathrm{GABA}_{\mathrm{A}}$ agonist THIP (gaboxadol) increases non-REM sleep and enhances delta activity in the rat. Neuroreport 7:2241-2245

Manuchehri K, Goodman S, Siviter L, Nightingale S (2000): A controlled study of vigabatrin and visual abnormalities. Br J Ophthalmol 84:499-505

Nutt DJ, Glue P, Lawson C, Wilson S (1990): Flumazenil provocation of panic attacks. Arch Gen Psychiatry 47:917-925

Sayin U, Purali N, Ozkan T, Altug T, Buyukdevrim S (1992): Vigabatrin has an anxiolytic effect in the elevated plusmaze test of anxiety. Pharmacol Biochem Behav 43: 529-535

Sherif F, Harro J, el-Hwuegi A, Oreland L (1994): Anxiolyticlike effect of the GABA-transaminase inhibitor vigabatrin (gamma-vinyl GABA) on rat exploratory activity. Pharmacol Biochem Behav 49:801-805

Sherif F, Oreland L (1995): Effect of the GABA-transaminase inhibitor vigabatrin on exploratory behaviour in socially isolated rats. Behav Brain Res 72:135-140

Shlik J, Aluoja A, Vasar V, Vasar E, Podar T, Bradwejn J (1997): Effects of citalopram treatment on behavioural, cardiovascular and neuroendocrine response to cholecystokinin tetrapeptide challenge in patients with panic disorder. J Psychiatry Neurosci 22:332-340

Ströhle A, Holsboer F, Rupprecht R (2000): Increased ACTH concentrations associated with cholecystokinin tetrapeptide-induced panic attacks in patients with panic disorder. Neuropsychopharmacology 22:251-256

van Megen H, Westenberg HG, den Boer J, Slaap B, Scheepmakers A (1997): Effect of the selective serotonin reuptake inhibitor fluvoxamine on CCK-4 induced panic attacks. Psychopharmacology 129:357-364

Wittchen HU, Zhao S, Abelson JM, Abelson JL, Kessler RC (1996): Reliability and procedural validity of UM-CIDI DSM-III-R phobic disorders. Psychol Med 26:1169-1177

Zwanzger P, Baghai T, Boerner RJ, Möller H-J, Rupprecht R (2001): Anxiolytic effects of vigabatrin in panic disorder. $\mathrm{J}$ Clin Psychopharmacology (in press) 